\title{
Et par breve fra A. F. Tscherning til Laurids Skau
}

Ved H. V. Gregersen.

I 1845 havde Laurids Skau søgt forbindelse med A. F. Tscherning til fremme af en højst besynderlig plan, som i månederne forud for udsendelsen af »det åbne brev af 8 . juli 1846 « beskæftigede ham meget. Selv oplyser han, at den havde til formål "at gjøre Hertugen selv eller hans anden søn til Hertug i Holsteen, hvortil da Lauenborg også måtte knyttes, og derimod de augustenborgske Besiddelser og Arvelande tilfalde ham eller i Mageskifte den fast organiserede og velsluttede danske Stat".

Til mellemmand for disse bestræbelser havde han udset pastor Hans Wexels Krog-Meyer i Ulkebøl, til hvem han 1846 7/1 sendte en længere redegørelse, som han dagen efter meddelte Tscherning en genpart af, for at denne fra første færd kunne holde sig orienteret. $^{1}$

Tschernings svar blev det her meddelte brev af 1846 20/1, der hidtil har været savnet." Kun hans påtegninger på Laurids Skaus brev har vidnet om dets eksistens. Det hedder her: "Besvaret 20. Jan. Advaret mod Intriguer, raadet til at blive strængt indenfor Lovlighedens Gebet, ikke vildlede Hertugen med falske Forestillinger og Forhaabninger, men tilskynde ham til at optræde som dansk-holstensk Prinds og Borger for at virke for Statsmagtens og Almenhedens Sag ". Brevet, der i flere henseender er bemærkelsesværdigt som udtryk for Tschernings forfatningspolitiske synspunkter $\mathrm{i}$ årene forud for Treårskrigen, findes nu i Rigsarkivet: Ministeriet for Hertugdømmet Slesvig, Sekretariatet: Politik 1848 -64 . 
A. F. Tscherning til Laurids Skau 1846 20/1.

Kjøbenhavn, d. 20 . Januar 1846.

H. Laurids Skau, Gaardeier, Haust pr. Haderslev.

Deres behagelige Skrivelse af 8 . har jeg læst med stor Fornøielse; jeg anseer Campagnen paa Als for meget vel begyndt; kan det blive et Middel til at overtyde Schleswigholstenerne om Taabeligheden og Uholdbarheden af deres Bestræbelser saavel for at danne et selvslandigl Rige Schleswigholsten som især for at sætte dette under tydsk Varetægt, saa har De vel viist. - Denne Stræben er i Sandhed ligesaa uklog som den at ville inddrage IIolsten og Lauenborg til et Heele med Resten af den Stat, hvori Kongen af Danmark harsker som saadan, og som er det egentlige uafhængige danske Kongerige. Begge Bestrabelser kunne ikke fore til virkelige Endemaal, thi i begge blive en vigtig uafgjort Sag tilbage.

Bruges Throneenheden som Statsenhedsmiddel, og det virkelig lykkes det bureaukratiske Parti, forbunden med Hofpartiet at faae den samme Arvelov antaget for den tydske (Forbunds) som for den danske (uafh[æ]ng[ige]) Deel af Staten og saaledes at realisere en Statsenhed a la Preusen, saa er delte dog kun en Skineenhed, thi Statsgrændsen mellem Holsten-Lauenborg og Danmark vil stedse gjøre sig gjeldende $\mathrm{i}$ indviklede politiske Tider og den virkelige Eenhed forsvinde. Lykkes det Schleswigholst: at faae deres eftertraglede Forening mellem de saakaldte Hertugdømmer tilveiebragt, saa er dermed ogsaa kun vundet noget Tilsyneladende, thi fra det tydske Forbund kan Schleswig ikke finde Beskyttelse mod sin Konges retmæssige Fordringer, og vil Holsten i en Tvistens Tid klamre sig fast til Schleswig, saa maae det ofre en stor Deel af de Fordele, som det sager at drage af Forbindelsen med Forbundet. Begge Systemer stiller Staten paa et Gyngebrædt. Virkelig Eenhed kan kun findes i en fuldstændig Anerkjendelse af Delenes forskelligartede Natur som europæisk politiske Legemer, deres Ordning ifølge heraf eller deres virkelige Omdannelse i Modsætning hertil (Holsten ud af Forbundet eller Danmark ind i Forbundet).

Forbundet er en Magt for de mindre Stater; hvo, som ikke vil underordne sig den, maa blive afsondret fra den. Det er et Fyrste- 
forbund, ikke et Statsforbund, siger man, og det er sandt, thi eet af dets practiske Hovedformaal hidtildags har været at opretholde Fyrstevælden i Modsætning til Folkevælden, ikke som Personification af Statsmagt, thi som saadan trænger Fyrstevælden netop til Udvikling af politiske fri Institutioner som i England, men som Arveeiendomsherrer ifølge det familieretlige Legitimitetsbegreb. I Danmark er Kongeherredømmet i sin hele Absoluthed kun Statsmagten concentreret i Personen, imod privatretlige Anmasselser og Standsprivilegier, i Tydskland er Fyrstemagten en Eiendomsret over en Arvelod. Staterne ere Arvelodder for visse privilegerede Familier, Frihederne ere Arveprivilegier for visse Landdele eller Samfundsklasser, hvorved Fyrsten lider en vis Indskrænkning i sin arvede Eiendeel. Frihedskampen i Tydskland er i sin lovlige Skikkelse en Privilegiekamp; hvor den udvikler sig til Kamp i Statens Navn, tager den en Ulovligheds Characteer, thi Stater findes egentlig ikke, ellers blev Forbundet til et Statsforbund. Frihedskampen i Danmark er en Kamp for Statsmagtens fortsatte Udvikling mod Privilegierne; i denne Skikkelse er den ganske lovlig, thi i den Skikkelse stræber ingen efter at forringe Kongemagtens guddommelige Magtfuldkommenhed; man stræber kun efter at beskytte den mod menneskelige Misbrug, at forskaffe det Sande Indskydelser, at tvinge den $\mathrm{i}$ en lovordnet Berørelse med det styrede Folk.

Det var heldigt om Hertugen af A[ugustenborg] kunne komme til at begribe, at medens hans fyrstelige Rettigheder kunne gjøres stridige og paa ingen Maade kunde fremmes ved at fremme den usalige Schleswigholsteinisme, dette usalige Misfoster af ensidig schleswigholstensk Bureaucratisme og Privilegiedrømme, medens, siger jeg, alt dette kan gjøres stridigt og maaske aldrig komme til Afgjørelse i hans Levetid, saa er der een Ting, som ikke kan forrokkes eller omtvistes, det er, at han ifølge Fødsel og Formue er et vigtigt Medlem af Kongefamilien og Danmarks fornemste Borger; heller ikke kan hans fortrinlige personlige Egenskaber berøves ham, og disse kunne han uden Møie bringe til at udbrede et dobbelt Skin, naar han stiller dem nærmere ved Siden af den langt ringere Deel af gode Egenskaber, som Danmarks Stræben har ladet blive samtlige Medlemmer af Kongefamilien til Deel med Deeltagelse af Kongen og maaske Hertugens Broder. En Mand, der 
for Øieblikket forener Caracteerfasthed, Indsigt og Retsindighed med en høi Stilling i Samfundet, som ikke er hildet af Nepotisme, som har det almene Vel alvorligt for Øie, og hvis Stilling hæver enhver Tvivl om Stræben efter at formindske den virkelige nyttige Statsmagt; en saadan Mand har i Danmark en vid Mark aaben for sig.

Fast alle nogenlunde trenkende Mænd see Fremtiden imøde med Engstelse og sukke efter en ophøiet Leder. Struensees og Berensdorfs Ministerier kunde ikke komme igjen, thi den offentlige Mening har en større Betydning og kræver en større Modvægt. Den of fentlige Menings Magt maa bekjæmpes af den of fentlige Mening selv legaliseret, det er Nutidens Nødvendighed, og det er den constitutionelle Grundvold, hvorpaa der maa bygges. Reformatorens Tid er kommen i Danmark, thi Tvivlene have naaet det høieste Maal i alle Retninger, og Trangen til Erkjendelse og Tillid er folt; kunde De blive Midlet til at formaae Hertugen, som vel kan siges at være den meest Competente for Øieblikket, til at indlede og udvikle en kraftig gjennemgribende Reform, da har De en stor Fortjeneste af Staten saavelsom af Hertugen. See vi os om, da ligger Reformbanen tydelig nok for os. Vi maae tilfredsstille Adsplittelsens billige Fordringer for at beskære dem i Navn af Eenhedens ligesaa velbegrundede Krav. Hint skeer ved at forandre Landets Bestyrelsesinddeling til en virkelig Provindsinddeling med til hverandre svarende Bestyrelsesorganer og Folkeraad, fx. Sjælland, Laaland Falster, Fyn, Nørrejylland, Slesvig, Island, Færøe, Vestindien, Holsten, Lauenborg. Heri gik da de nuværende Stænder og med alle deres forvirrende og gjærende Erindringer, og heraf kunde igjen udvikles de Statsenheder, som Monarchiet indeholder ifølge Statshøihedsbegrændsningen. Dette, nemlig Eenhedsudviklingen, skeer gjennem en fuldstændig Afsondring og Udvikling af den dømmende Myndighed, med Tilkaldelse af virkelig Retsoffentlighed og Folkedeltagelse. Eenhedsudviklingen fremmes dernæst ved et vel ordnet Væbningsvæsen. Begge Indretninger giver Nutidens store Krav, Lighed, Fyldestgjørelse. Begge styrke Statsmagten og gjør den skikket til at mødegaae de politiske Storme, som muligen kunne følge af det yderligere Skridt frem paa Reformbanen, af Statsinstitutionernes Udvikling til constitutionel Sam- 


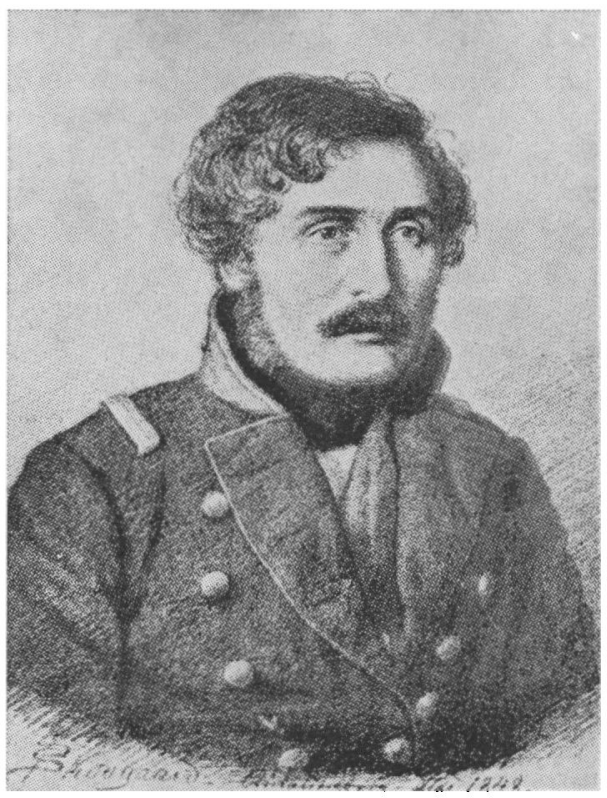

Anthon Frederik Tscherning

(litografi efter tegning

af P. Chr. Skovgaard)

virken, til Frihed. Paa hvilket Trin jo netop alle Uligheder faae og bor have saa frit Spillerum som muligt.

Sandelig, her er en vid Mark, den ligger aaben for Ploven, og ingen staaer nærmere til at være den egentlige Plougmand end $H$ [ertugen] af $A$ [ugustenborg], saafremt han kan hæve sig ud over de schleswigholstenske Garn, hvori han selv har hildet sig, saafræmt han kan som dansk-holstensk Prinds og Borger forene sig med den nyere Tids Fostre og eftertragte Gjensidighed af Udvikling mellem Stat og Individet istedetfor som Fortidens Privilegiemand at søge ensidig Anerkjendelse af umulige Privilegier, udklækkede af menneskelig Kortsynethed. Dog i enhver Underhandling med denne Mand, det være directe eller indirecte, lov ikke meer, end hvad De og vi kun(ne) holde, og frist hverken Dem eller ham ind paa noget ulovligt Terrain. Lad ham aldrig komme til at troe, at De søger Personen uden forsaavidt den behøves for Staten. Kun inden for Lovens Grændser ere vi stærke. Ud over Loven bør man aldrig glemme, at kun Legemsmagten gjelder. Hvad saaledes den Dom angaaer, hvilken De har fælled personlig om mig i den indlagte Afskrift, da er den i væsentlige Ting ikke rigtig. Jeg taler 
ikke om det for høie Værd, De tillægger min Duelighed og mine Indsigter; De maa ved at dømme saavel mig som Andre aldrig glemme Hollænderens Ord "Snak is good Koop", i Gjerningen er jeg kun lidet prøvet. Hvad jeg her egentlig mener, er den Indflydelse, De tillægger mig, thi den har jeg ikke. De Mænd, som kunne tillægges Indflydelse i de forskjellige Samfundskredse, ere Etatsrd. Treschow, Etatsrd. Bang, Professor Clausen, Etatsrd. Hvidt, Adv. Lehmann, Comrd. Drewsen, Procurator Christensen, Gaardmd. O. Kirk, Magist. Monrad etc. Jeg har egentlig ingen Indflydelse. Den ringe Indflydelse, jeg i enkelte Tilfælde kan udøve, beroer netop paa, at jeg ingen egentlig Betydning har og ikke rivaliserer med nogen. Jeg er knap almindelig vel lidt, mindre almindelig anerkjendt eller fulgt. -

Lad os i det Hele ikke overvurdere vore egne Kræefter. See til O'Connel i Irland, Antikornlawliga i England, see hvilke gyldne Beviser paa Tillid de modtage, og desuagtet kunne de ikke danne et Ministerium. Styrken her i Landet ligger endnu ikke hos os og vore Venner. Havde vore Anskuelser en daglig Talsmand ved Thronen som $\mathrm{H}$ [ertugen] af $\mathrm{A}$ [ugustenborg] istedetfor en Bysnak. ker og Nyhedskniv som Prinds Bentheim og saamange andre, saa betydede vi mere, men dog vare vi endnu langt fra at udgjøre det herskende Flertal. Men ogsaa dette kunne i dette Øieblik en stræng alvorlig Uafhængig vinde for sig, og derpaa maatte Hert[u] g[en] netop gjøres opmærksom.

Vi maa ogsaa vogte os for, at vor Færd i nogen Maade faaer Skin af Intriger, vore Modstandere maae vide saagodtsom vore Venner, hvad vi ville, først derved vinde vore Meninger Styrke.

Jeg har til fulde indseet Deres Meddelelsers ganske private Caracteer og skal vide at holde dem ganske for mig selv; jeg ønsker Dem god Lykke saavel til Deres Landvæsens Fremme som til Deres offentlige Virksomhed, beder Dem hilse fælleds Venner og gjentage Forsikringen om hengiven Høiagtelse.

\section{* * A. F. Tscherning.}

Et halvt års tid senere fortsattes korrespondancen, idet Laurids Skau 1846 4/7 meddeltes Tscherning, at han havde modtaget et anonymt brev fra Als, "skreven med en videnskabelig dannet Mands Haand og Stiil«, hvori brevskriveren gik ind på Laurids 


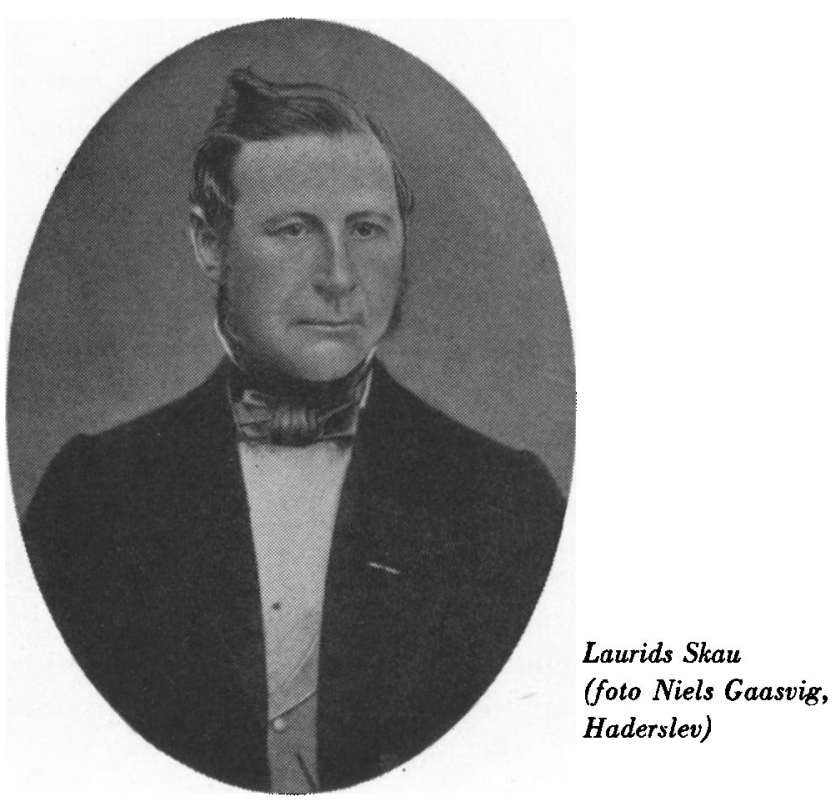

Skaus tanker med hensyn til arvespørgsmålet. Hertugen af Augustenborgs anden søn stod $\mathbf{i}$ begreb med at overtage et gods $i$ Sverige, og herfra kunne han nemt hentes til København, meddelte den anonyme ophavsmand til brevet - efter Laurids Skaus opfattelse »i og for sig en ganske fornuftig Idee".

Tschernings svar på denne oplysning blev efterstående brev, der hidtil kun har været kendt i koncept. Som sådan er det tidligere trykt i A. F. Tschernings efterladte Papirer II, s. 257 ff., og i Danske Politiske Breve fra 1830erne og 1840erne III, s. 162 ff., men originalen, der hidtil har beroet blandt familien Skaus privatpapirer, bringer et par steder så afgørende korrektiver til koncepten, at et optryk af Tschernings originalbrev nok kan være på sin plads.

A. F. Tscherning til Laurids Skau 1846 11/7.

Kjøbenhavn, d. 11. Juli 1846.

Hr. Gaardeier L. Skau paa Houst.

Deres behagelige Skrivelse af 4. dennes har jeg liggende for mig 
og skynder mig at besvare den. Idet jeg atter omtaler Arvesagen, som [De] paanye har bragt paa Bane og som unæglelig er særdeles vigtig for enhver god dansk Fædrelandsven, maa jeg begynde med at bringe Dem vores Udgangspunct og vore Grundsæetninger i Erindring, thi kun med Blikket heftet fast paa dem kan der udrettes noget. Vi ville Statens Eenhed, men ikke Familiernes Bequemmelighed og Interesse. Vi ville Opretholdelsen af en paa Statsbegrebet støttet monarchisk Forfatning som den, der for $\emptyset$ jeblikket bedst passer paa de monarchiske Forhold. Vi ville endelig ved lovlige Midler naa et lovligt Formaal. Dersom man fra Regje. ringens Side havde vidst at nedslaae alle Arvespørgsmaal, saa at ingen Tvivl var opstaaet om dem hos Borgerne, saa var det aldrig faldet os ind at tænke paa nogen Personforandring, thi vi vide for vel, at man kun sikrer Lidet for Staten eller dog kun noget høist usikkert og forbigaaende ved at sikre den en vis Person og binde Tusenders Vel til hans tilfældige Beskaffenhed, men man har ladet Tvivl opstaae om Arvefølgen ikke alene i den Deel af Monarchiet, som hører under tydsk Høihed, men selv i Dele af den fuld souveraine danske Stat. Først efter at disse Tvivl ere reiste, er det, at vi have sagt: Arvefølgen er en Lovgivningsag, som enhver anden $\mathrm{Be}$ stemmelse Riget angaaende. Har man tidligere kunnet lovgive her. om, kan man atter gjøre det, men Tvivl bør man ikke taale, thi da bortfalder Monarchiets Hovedfordeel at sikre en vedvarende uforstyrret Personification af Statshøiheden. Vi have yderligere sagt: siden I tvivle, og der trænges til Lovbestemmelser, saa betænk, om I ikke ved dem kan naae det Formaal, I saameget eftertragte, og som maaske kan have sin gode Side og vedligeholde Personforbindelsen med Holsten, indrette Danmarks Arvelov, som Staten selv raader over, eens med Holsteen, som Forbundets Bestemmelser gjøre urokkelige. Det er ikke os, denne Side af Sagen ligger paa Hjerte, vi paavise kun een som det synes god Udvei for dem, som have deeltaget $i$ at forvikle vore Forhold ved at lade Uklarheden udvikle sig over Eidergrændsen. Vi fra vort Standpunct fordre kun Klarhed, Lovsikkerhed mod Arvetvivl for Danmark og overlader Holsteen til den Skjæbne, som Indtrædelsen i Forbundet medfører. Vi see maaske med Fornøielse en Personforandring i Danmark imøde, fordi vi ansee det for et stort Misgreb, at man har søgt Ly under Ruslands Vinger og saaledes kaldet dette grid- 
ske, farlige Naborige end mere ind $i$ vore indre Forhold. Vi ansee det maaske endog for et nyttigt Udviklingsmoment at faae lovgivet om Arvefolgen, men da det ikke er og ikke kan være en Personalforaudring, vi attraa, men kun Arvesikkerhed og uomtvistelige Statsgrændser, saa forekommer det mig, at vi ikke kunne komme til blot med en Tanke at berøre noget enkelt Lem af den augustenborgske Familie, thi det er ikke Personen, vi skulle vælge, men Familietvivlene, vi skulde have. Var det gjort tydeligt, at Kongelovens Arvefølge gjal $[\mathrm{d}] \mathrm{t}$ uomtvistelig til Eideren, saa havde vort Parti inlet meer at gjøre med denne Sag, men traadte man os da imøde og vedgik, at en anden Arvelov gjeldte for Holsten, og at man, da denne var urokkelig, gjerne ønskede den danske forandret, saa kunde vi med stor Beredvillighed række Haanden hertil, men ved alt dette kunne høist blive Spørgsmaal om Familien, me'n aldrig om den eller hiin Person af samme. I Familien gjalder l'orstefodsel, det er simpelt og naturligt, med mindre der fastsættes en prindselig' Ranglov, hvorved Arvefølgen aarlig angaves i Statscalenderen. Dette kunde ogsaa være godt, men det er da aller ikke nogen bestemt Person, med en saadan forekommer det mig, at vi aldeles ikke have noget at gjøre. Fra Personvalg maa vi loolde os fjernede, om vi iklie skulde lade os friste ind i Prindseintriger. Det er nok, at Ilertugen veed, at vi paa den ene Side ikke billige noget Arvekrav paa en enkelt Deel af det uafhængige danske Rige, men at vi ingen Hindringer skulde lægge dem iveien, som for at sikre Forbindelsen med Holsten benyttede den Arvetvivl, som har indsneget sig, til at faae Arveloven forandret derhen, at den i Danmark faldt sammen med den i Holsten. Langer kunde vi ikke række med vore Grundsætninger, og udenfor dette blive vore Bestræbelser let ulovlige. Hertugen synes imidlertid ikke at kunne finde denne Vei, han synes uden Forbindelse med det bureaucratiske Parti, som alene kan bringe Forslag af denne Art paa Bane. Det er hans Feil, han foretrækker at styrke sig i Tydskland fremfor i Danmark, han maa selv bedst vide hvorfor, men vort Parti kan ikke hjælpe ud af den herved fremkaldte Forlegenhed og Stilstand, thi vi forkaste Tvivlen og see i Personen den tilfaeldige Slutsteen i den monarchiske Stat. De skandinaviske Demonstrationer have kun lidt at gjore med vore indre Sager. Som Forholdene nu ere i Europa, maa Skandinavien fremgaae af politisk Overbeviis- 
ning og foederative Tilskyndelser, men ikke af Familieforbindelser, hvis Time alt er slagen. Forstebeslæglning og Afstamning etc. etc. kan være et Moment, men hverken kan eller bor være meer. Nu da Begivenhederne for tydeligt have lært os, at den Bindekraft, som hentes fra Familielegitimiteten, kun er ringe. At drage de skandinaviske Ideer ind i vore indre Forhold, er kun at forvikle disse mere paa samme Tid, som man fjerner de skandinaviske Forbindelser. At Hertugen af A[ugustenborg] istedetfor at optræde som kraftig Støtte for Reformpartiet i selve Danmark vedbliver at lefle med schleswigholstensk Tydskhed og at søge Familieforbindelser, det bliver hans Sag, men vor er det ikke at lade os friste ud over den Grændse, hvor vi kunne mødes i det offentlige Vels Navn og i Fælledskab fortsætte vore lovlige Bestræbelser. Anonyment Brev elsker jeg ikke og troer kun halvt derpaa.

Med Venskab og Høiagtelse

A. Tscherning.

1. Optrykt i: Af Anthon Frederik Tschernings efterladte Papirer II (1877), s. 249-256; jfr. Tormod Jørgensen: Anthon Frederik Tscherning (1938), s. 76-77. Skaus brev til pastor Krog-Meyer i Ulkebøl findes i uddrag i Ludvig Hertel: Hans Wilhelm Hertel. Bidrag til den sønderjydske Folkevækkelses Historie (1897), s. 137-141 (efter: Droysen \& Samwer: Die Herzogthümer Schleswig-Holstein und das Königreich Dänemark. Aktenmässige Geschichte der dänischen Politik seit 1806 (1850), s. 204-207, 404-408.

2. Se således: Danske Politiske Breve fra 1830erne og 1840erne III, s. 162.

3. Laurids Skau havde i sit brev til Krog-Meyer fremhævet Flor og Tscherning som betydningsfulde for *Ideens Realisation *. I randen på Skaus genpart af dette brev har Tscherning tilføjet: \$Jeg har ikke denne Betydning; dette skrevet til Skau og udhævet de Mænd, som fortiden have Indflydelses.

4. Ifølge koncepten (sikkert fejllæsning): qvindelig. 